\title{
12 - Ressecção parcial e omentalização de cisto prostático de retenção em três cães
}

Galeazzi, V.S.'; Matera, J.M.'; Castro, P.F.'
Castro, P.F.' ; Matera, J.M.'; Rosner, S.A. '; Galeazzi, V.S. '; Froes, T.R.'
1- Hospital Veterinário da Faculdade de Medicina Veterinária e Zootecnia da Universidade de São Paulo, São Paulo-SP

A doença prostática acomete cerca de $80 \%$ dos càes machos não-castrados com idade superior a dez anos, sendo menos comum em cães com idade inferior a quatro anos, onde a incidência representa $0,6 \%$. Os cistos prostáticos de retenção são formados devido à obstruçào de ductos dentro do parênquima glandular levando à estase secretória e dilatação acinar progressiva. Variam de um achado acidental em cães, sem quaisquer sinais clínicos de doença, a cistos de dimensões consideráveis causando sinais de disfunções urinárias, incluindo estrangúria, disúria, hematúria, incontinência, tenesmo, além da presença de massa abdominal caudal. O diagnóstico é confirmado pelos exames radiográfico e ultrassonográfico e, a ressecção cirúrgica, com ou sem a orquiectomia concomitante, é o tratamento recomendado. Um grande número de técnicas tem sido descritas para a drenagem ou ressecção de cistos prostáticos. A ressecção parcial de cistos prostáticos e a omentalização tem provado ser um método cirúrgico eficaz e promissor, com pequenas taxas de complicações e recidiva.

Este estudo relata a aplicação da técnica de ressecção parcial e omentalização como tratamento de cistos prostáticos de retenção em três cães, nos quais a técnica de drenagem do cisto guiada por ultrassonografia resultou em recidiva e não resolução definitiva do cisto. Três cães portadores de doença prostática caracterizada pela presença de cisto prostático de retenção foram atendidos no Serviço de Cirurgia de Pequenos Animais do Hospital Veterinário da Faculdade de Medicina Veterinária e Zootecnia da Universidade de São Paulo. A avaliação diagnóstica fundamentouse em exame fisico completo, palpação abdominal e retal, exames laboratoriais de rotina como hemograma e bioquímica sérica, exames radiográfico e ultrassonográfico.

Foi realizada laparotomia mediana retro-umbilical. O cisto foi identificado sendo realizada a completa drenagem do mesmo sem contaminação da cavidade abdominal. A maior parte da parede do cisto foi ressecada após cuidadosa divulsão ao redor da uretra prostática e próstata. $\mathrm{O}$ omento foi, então, acondicionado à parede do cisto remanescente e mantido em posição com sutura de pontos simples separados com fio poliglecaprone 3-0.

O pós-operatório dos três pacientes ocorreu sem quaisquer complicaçôes e, no décimo dia pósoperatório, foram removidos os pontos cirúrgicos. Foi realizado exame ultrassonográfico controle no $15^{\circ}$ dia pós-operatório sem alterações dignas de nota e os pacientes receberam alta. O exame clinico dos animais após 60 dias da intervenção cinúrgica revelou excelente estado geral.

A ressecçào parcial e omentalizaçào de cisto prostático tem demonstrado ser uma técnica viável, apesar de apresentar certo grau de dificuldade na ressecção do cisto, com redução significante de recidivas, baixo período de hospitalizaçào, cura do paciente e poucas complicações quando comparado com outras técnicas cirúrgicas, sendo a opção quando a drenagem não cirúrgica do cisto, guiada por ultrassom, é recidivante.

\section{3 - Ureterotomia como tratamento de obstrução ureteral em dois cães}

1- Hospital Veterinário da Faculdade de Medicina Veterinária e Zootecnia da Universidade de São Paulo, São Paulo-SP

A ureterolitíase é condição rara nos cães e gatos e poucos são os relatos de sucesso na remoção de cálculos ureterais. $\mathrm{A}$ detecção de urólitos não é por si só indicaçào para a ureterotomia, sendo a obstrução sem possibilidade de solução médica, o hidroureter e a hidronefrose as mais citadas. Entre as complicações desta cirurgia destacam-se a estenose e o vazamento no sítio da sutura. Os cálculos renais representam menos de $4 \%$ dos casos de 
urolitíases nos càes e gatos, enquanto na espécie humana totalizam $97 \%$ dos casos. A ureterolitíase em humanos é tratada inicialmente mediante a administração de agentes antiespasmódicos e de líquidos orais ou intravenosos e as técnicas cirúrgicas vêm sendo substituídas por aquelas menos invasivas, como a ureteroscopia, a nefrolitotomia percutânea e a litotripsia. Infelizmente tais técnicas ainda não se encontram acessíveis para o uso de rotina em animais de estimação, com relatos raros e isolados do seu emprego em veterinária, dai a importância de priorizarmos a remoção precoce destes ureterólitos que causam obstrução, através de técnica cirúrgica adequada, aumentando a chance de restabelecimento da função renal e ureteral. Neste trabalho, relatamos dois casos de obstrução ureteral unilateral por ureterólitos, atendidos no Serviço de Cirurgia de Pequenos Animais do HOVET-FMVZ/ USP, nos quais realizamos a ureterotomia unilateral. Os animais eram da espécie canina, um da raça Schnauzer, fêmea, 7 anos de idade, com precedente de litíase renal tratada há 2 anos $\left(n^{\circ} 1\right)$ e outro SRD, macho, 11 anos de idade, com obstrução uretral por litíase tratado há 1 ano $\left(\mathrm{n}^{\circ} 2\right)$. Ambos apresentavam hiporexia, êmese, disúria e prostração há 5 dias e os exames fisicos revelaram sensibilidade abdominal, desidratação leve, temperatura corpórea normal acompanhado no animal $\mathrm{n}^{\circ} 2$ de taquipnéia e repleção vesical. Os exames laboratoriais mostravam moderada leucocitose por neutrofilia e uremia leve: animal $\mathrm{n}^{\circ} 1$ uréia $=77,97$ $\mathrm{mg} / \mathrm{dl}$, creatinina $=1,5 \mathrm{mg} / \mathrm{dl}$ e animal $\mathrm{n}^{\circ} 2$ uréia $=98,0 \mathrm{mg} / \mathrm{dl}$, creatinina $=1,7 \mathrm{mg} / \mathrm{dl}$. O exame radiográfico simples demonstrou a presença de nefrólitos, ureterólitos e hidronefrose direitos (D) acompanhado de urólitos em vesícula urinária na fêmea e de urólitos em uretra perineal e peniana no macho. A avaliação do rim acometido (D) pela ultra-sonografia revelava hidronefrose e limites córtico-medulares pouco definidos. A urografia excretora demonstrou ausência de imagem de filtração renal $\mathrm{D}$ sugerindo afuncionalidade no animal $\mathrm{n}^{\circ} 1 \mathrm{e}$ filtração renal com pelve dilatada e hidroureter $\mathrm{D}$ no animal $\mathrm{n}^{\circ} 2$. Ambos foram submetidos à ureterotomia $\mathrm{D}$, sendo que no primeiro, a incisão no ponto de dilatação próximo ao rim revelou grande quantidade de coleção purulenta realizando-se colheita de amostra para cultura e antibiograma, procedendo-se à lavagem com solução fisiológica das porções proximal e distal do ureter até que não houvesse indícios de pus ou debris, tendo sido o ureterólito desalojado por hidropropulsào para a vesícula urinária. No segundo foi necessário ureterotomia próxima ao rim para a retirada de um cálculo e em inserção uretero-vesical para a retirada de outros dois, bem como uretrostomia pré-escrotal devido à impossibilidade de desalojar os cálculos localizados em uretra peniana. Em ambos a síntese ureteral no plano longitudinal foi realizada com fio de poligliconato monofilamento 5-0 no padrão pontos simples separados, priorizando-se mínima tensão da sutura e trauma ao ureter. $\mathrm{O}$ acompanhamento clínico, laboratorial, radiográfico e ultra-sonográfico associado à terapia médica até 210 dias pós IC em ambos os animais demonstraram ausência de sinais de estenose ou vazamento nos sítios operados e diminuição da dimensào renal e limite córtico-medular sugerindo evolução desfavorável da funcionalidade do rim acometido.

\section{4 - "Walking Suture" modificada para a reconstituição de amplos defeitos de pele após mastectomias em 86 fêmeas caninas}

Rodaski,S.'; Wouk,A.F.P.F.'; Souza,R.S.'; De Nardi,A.B. ${ }^{2}$. Piekarz,C.H. ${ }^{3}$; Castro,J.H.T. ${ }^{4}$; Oliveira,M.E.S. ${ }^{5}$
1- Docentes da Universidade Federal do Paraná, Curitiba-PR

2- Pós-Graduando em Cirurgia Veterinária da Universidade Estadual Paulista, Jaboticabal-SP

3- Bolsista PIBIC/CNPq

4-Monitor da Disciplina de Técnica Operatória Veterinária da Universidade Federal do Paraná, Curitiba-PR 5- Médico Veterinário da Universidade Federal do Paraná, Curitiba-PR

Considerando-se que em geral os tumores mamários na fêmea canina são múltiplos e de grande volume, os defeitos de pele resultantes das exéreses também são amplos. No decorrer das mastectomias realizadas em fêmeas da espécie canina, foi observado dificuldades técnicas 